\title{
Biotoxicity assay of Escherichia coli against Tribolium castaneum
}

\author{
Kausar Malik ${ }^{1}$, Sana Pervaiz ${ }^{2}$, Mir Muhammad Ali Talpur ${ }^{3}$, Amjad Farooq $^{4}$ and \\ Farkhanda Jabeen ${ }^{5}$ \\ ${ }^{12}$ Department of the Zoology, Lahore College for Women University Lahore, Jail Road, Lahore, Pakistan.
}

\begin{abstract}
Pathogenic Escherichia coli is found in the contaminated raw meat, raw milk, raw vegetables, contaminated water. Contamination is common in Pakistan due to un hygienic condition. The present work was based on the entomopathogenic effect of E.coli against stored grain pest Tribolium castaneum. The Bioassay was applied in two groups e.g. Control group and Experimental group. The pellet of grown culture of E.coli sample was mixed in the diet of Tribolium castaneum. The effect of E.coli was observed against $2^{\text {nd }}$ Instar larvae of Tribolium castaneum upto three days and seven days. The mortality rate in both control group and Experimental group was approximately $\leq 10 \%$. The results had shown that E.coli did not have any effect against Tribolium castaneum.
\end{abstract}

Key words: Escherichia coli, Biotoxicity, assay, Tribolium castaneum.

\section{Introduction}

Pakistan is a country where consumption of food is maximum in the form of wheat, rice, oats, pulses etc. These crops play an important part in the increasing economy of Pakistan. Every year these crops become a victim of the stored grain pests. To protect the crops from these pests, many pesticides are present but the present study was concerned with the pathogenic E.coli which is pathogenic to human. This study was done to find the entomopathogenic effect of E.coli on stored grain pest Tribolium castaneum. Biotoxicity assay technique was applied so that the effect can be clearly seen.

Pakistan is a country where consumption of raw meat is maximum. Raw meat is sold in open markets where a large number of pathogen bacteria are present. These pathogenic bacteria grow in this raw meat and consumption of this meat causes serious health hazards. A vast variety of pathogens are present in our surrounding that causes infection to living organism. Among these pathogens, Escherichia coli (E.coli) are the most common pathogen. E.coli is a pathogen of mammals and human beings that causes the infection in intestinal tract [1]. E.coli is facultative anaerobic bacteria [2], Gram negative bacterium and non-sporulating, rod shaped cells with the diameter of $0.5 \mu \mathrm{m}$ and are $2 \mu \mathrm{m}$ long. The volume of cell is $0.6-0.7 \mu \mathrm{m}^{3}$ [3]. E.coli which is a inhabitant of human being's intestinal tract is one of the most dangerous water borne and food borne pathogen that is a causative agent of intestinal and extra intestinal infections [4].

E.coli is the most common bacteria that is found in the gut of animals. This includes humans as well. There are many animal species which contain this organism in the gut including fish and reptiles. E.coli colonizes the gut within a few hours depends upon the species involved. The intestines can be colonized within 40 hours of birth in the humans. E.coli attaches to the mucus of the large intestine. Other bacteria that are growing in the gut may be intestinal pathogens including Shigella, Salmonella Yersinia, Klebsiella and Enterobacter. All of these bacteria may be associated with human illness [5].

The red flour beetle, Tribolium castaneum is an important pest of stored grain. These beetles live mainly in grain stores mills and bird nests [6](Roth and Kurtz. 2008). Tribolium castaneum belongs to order Coleoptera that contribute more than one third of all eukaryotic species. Tribolium castaneum is the most flexible and sophisticated genetic model for the beetles. A number of physical adaptations has been found in this insect and these adaptations are not found in any other insect species such as Drosophila melanogaster, Anopheles gambiae and Apis mellifera. For example, Tribolium castaneum belongs to a group of insects that are dessication-resistant insects [7]

Serotyping is important factor in distinguishing between the strains of bacteria that cause diseases in human. E. coli can cause infection in the brain stem and urinary tract infection and intestinal diseases. All these strains causes diarrhea. There are five different types of $E$. coli strains that produce disease. They are classified by the method of pathogenesis. Enterotoxigenic (toxins) Enterohemorrhagic (hemorrhagic), Enteroinvasive (Invasive), Enteropathogenic (Pathogenic), Enteroaggregative (Aggregative).

Enterotoxigenic E.coli produces toxins and are important in causing diarrhea in infants especially in regions where sanitation is poor. ETEC produces one or more enterotoxins belonging either to the heat stable family (STa, STb) or heat labile family (LT-1,LT-2) [8,9]. Enteropathogenic E.coli organism attaches to the intestinal mucosa which causes an inflammatory response. This causes watery diarrhea. Although it is now known that some EPEC strains do produce toxins, Such as verotoxins, distinct from ETEC enterotoxins [10. 11] 
and that some EPEC strains do invade. Enteroinvasive E.coli organisms do not produce shiga toxin. They enter into the cell wall of the colon resulting in damage of cell and diarrhea. These organisms invade the epithelial cells; proliferate within epithelial cells, and causes necrosis of the epithelial tissue lining which ultimately lead to bloody diarrhea [12]. Enterohemorrhagic E.coli include a single strain (serotype O157:H7) that causes diarrhea distinct from others in such a way that it results in bloody diarrhea. It causes hemolytic uremia in which kidneys are effected.. The $E$. coli produces the two toxins but it doesnot attack the intestinal mucosa and these toxins causes the inflammation [5,13]. Enteroaggregative E.coli is the ability of this organism is to attach to the tissue culture in aggressive way. This strain causes diarrhea in young. They attaches to the intestinal mucosa and causes inflammation and non-bloody diarrhea.

A large number of studies provide evidences that slaughtered animals like cows, buffalo and goats are reservoirs for Enteropathogenic E.coli (EHEC) and most importantly the virulent strain E.coli O157:H7 [14]. Previous studies on E.coli $\mathrm{O} 157: \mathrm{H} 7$ have described that prevalence that ranges from 2-3\% to as high as $80 \%$. The pattern of shedding of E.coli O157:H7 in the faeces of beef cattle are highly variable [15].

The insects are present in the stored grain and their presence results in great economic damage to the stored grain and subsequently results in loss of the products and contamination of the storage of food that causes a decrease in the nutritional value [16]. Fumigants are the chemical substances that are commonly used to protect the stored products from the other insect contamination but their wide use leads to the problem of undesirable residues and resistence is produced in certain insect species [17].

Bioassay is the determination of the relative strength of a substance by comparing its effect on a organism to be tested with that of a standard preperation. Bioassays are a kind of scientific experiment which are conducted to determine the effects of the particular substance on the living organism. Bioassay is a tool of checking the potency or the nature of the substance by applying it to the living organism. The widespread release and use of synthetic and natural chemicals into the environment singly or as complex domestic and industrial effluent has increased the development of rapid and cost effective toxicity tests to protect humans and other living organism [18].

\section{Material and Methods}

The cultured sample of E.coli was provided, which was identified and confirmed by immuno dot blot assay in the raw meat samples. For the preparation of TSB Agar media, 3.0g of TSB, $0.3 \mathrm{~g}$ of yeast and $1.5 \mathrm{~g}$ of Agar powder were dissolved in $100 \mathrm{ml}$ of distilled water in a conical flask and mixed it well with the help of magnetic stirrer. After autoclaving, the media is poured in pre-autoclaved Petri plates. Half filled the Petri plates and placed these plates in incubator at $37^{\circ} \mathrm{C}$. After over night incubation of plates, Bacterial culture was introduced in the poured plates by the inoculating loop which is called streaking. The inoculating loop was sterilized by dipping it in alcohol and then red hot in flame. Then let it be cooled. Then by carefully picking the bacterial colony, streaked the plates in an appropriate manner. All this work was done in the laminar flow near the lamp to avoid contamination. Again placed these plates in incubator at $37^{\circ} \mathrm{C}$.After overnight growth, off white colonies appear that confirmed the growth of microorganism.

\section{Preparation of liquid media:}

For the preparation of TSB liquid media, $3.0 \mathrm{~g}$ of TSB, $0.3 \mathrm{~g}$ of yeast were dissolved in $100 \mathrm{ml}$ of distilled water in the conical flask. Mixed it well with the help of magnetic stirrer. Adjusted the $\mathrm{pH}$ of the media by adding $\mathrm{NaOH}$ or $\mathrm{HCl}$ solution. Autoclaved the prepared media for 2 hours. Then poured the media in test tubes, $5 \mathrm{ml}$ in each test tubes. Then covered the mouth of test tubes with cotton and placed the test tubes in incubator at $37^{\circ} \mathrm{C}$. After one day, the test tubes containing media were inoculated. This inoculation should be done in the laminar flow to avoid any contamination. Then the test tubes were placed in the shaker for overnight bacterial growth. For the preparation of glycerol stocks, $700 \mu l$ of freshly prepared culture in the test tubes and $300 \mu \mathrm{l}$ of glycerol were added in the Eppendrof .These samples were stored for the future use in freezer. These glycerol stocks could be prepared by adding 700ul of bacterial growth and 300ul of glycerol in the Eppendrof, for the future use.

\section{Preparation of Sorbitol Mac.Conkey Media:}

For the preparation of Sorbitol Mac.Conkey Agar, Added 25.5g of Sorbitol Mac.Conkey Agar in 500 $\mathrm{ml}$ of distilled water in a conical flask and mix the media by a magnetic stirrer and dissolve it at stirrer machine. Covered the mouth of the conical flask with a cotton and aluminium foil. Then autoclave it and cool at the room temperature. This media was used for the growth of gram negative bacteria.After the autoclaving, the prepared media was poured in the pre autoclaved Petri plates and filled them less than half. Placed these Petri plates in the incubator at $37^{\circ} \mathrm{C}$ for 24 hours. This media is red in colour and was used to suppress the growth of the gram positive bacteria.After $24 \mathrm{hrs}$, the prepared plates were streaked with the bacterial culture and placed it in the incubator at $37^{\circ} \mathrm{C}$ at $24 \mathrm{hrs}$. 


\section{Detection of Pathogenic E.coli:}

Novobiocin containing media was used for the detection of pathogenic E.coli. It is specific for the growth of pathogenic Escherichia coli. For the preparation of Novobiocin containin media,3.67 gm of Novobiocin media was added in $100 \mathrm{ml}$ of distilled water in a conical flask, mixed it with the magnetic stirrer and autoclaved. The media was poured in the sterile test tubes. $5 \mathrm{ml}$ in each test tubes and then placed them in the incubator for $24 \mathrm{hrs}$ at $37^{\circ} \mathrm{C}$ overnight. Inoculated the Novobiocin media containing test tubes with the $100 \mu \mathrm{l}$ of the previously grown TSB media and sealed it with parafilm and placed it in incubator for overnight growth. Growth appeared after the overnight growth as it is the selective media for the growth of pathogenic E.coli. After overnight growth, streaked the TSB Agar media plates with the bacterial culture grown in Novobiocin containing media. The plates were sealed with the parafilm and were placed in incubator at $37^{\circ} \mathrm{C}$ for $24 \mathrm{hrs}$. For the preparation of glycerol stocks, $700 \mu \mathrm{l}$ of bacterial culture and $300 \mu \mathrm{l}$ of glycerin were added in Eppendrofs for future use. These samples were sealed with parafilm and stored them in refrigerator for future use.

\section{Rearing of Tribolium castaneum:}

Rearing of Tribolium castaneum was done in the laboratory of Lahore College For Women University under appropriate temperature. The autoclaved glass jars were used for this purpose. Weighed amount of semolina was put in the glass jars which were properly autoclaved and capped. The incubation time period of the Tribolium castaneum was about 26 days and after this period, a large number of insect population containing 1 st instar, 2nd instar and adult was seen. Tribolium was reared in the medium containing semolina and $10 \%$ yeast extract. 50 adult of Tribolium were placed in each jar containing $1 / 4$ of flour of jar. Closed the jar with muslin cloth and placed these jars in insectory set at $37^{\circ} \mathrm{C}$.

\section{Bioassay:}

In Experimental group, the pellet of grown culture of E.coli sample was mixed in the diet of T.castaneum and four concenteration were prepared. e.g. $0.25 \mathrm{~g} / \mathrm{g}, 0.50 \mathrm{~g} / \mathrm{g}, 1.0 \mathrm{~g} / \mathrm{g}, 1.50 \mathrm{~g} / \mathrm{g}$. Weighed the diet of Tribolium castaneum which includes semolina and yeast extract. Weighed the 1 gram of this feed, $0.9 \mathrm{gm}$ of semolina was mixed with $0.1 \mathrm{gm}$ of yeast extract. $0.25 \mathrm{gm}$ of sample is mixed in $1 \mathrm{gm}$ of diet. $0.5 \mathrm{gm}$ of sample is mixed in $1 \mathrm{gm}$ of diet.1.0 gm of sample is mixed in $1 \mathrm{gm}$ of diet. $1.5 \mathrm{gm} / 1 \mathrm{gram}$ of diet. These samples were placed in glass vials and then in each glass vial, $102^{\text {nd }}$ Instar larvae of Tribolium castaneum were added. Covered the glass vials with the parafilm sheet at $37^{\circ} \mathrm{C}$. Biassay was done in triplicate. Observed these samples daily for seven days to check whether there was any mortality or not. In Control group, the diet of Tribolium castaneum contains semolina and yeast extract. Made $1 \mathrm{gm}$ of diet, $0.9 \mathrm{gm}$ of semolina is added in $0.1 \mathrm{gm}$ of yeast extract.. Placed this diet in 3 glass vials in triplicate and in each glass vial $102^{\text {nd }}$ Instar larvae of Tribolium castaneum are added, covered with parafilm sheet at $37^{\circ}$ bo dna Cserved these vials for 7 days.

\section{Results And Discussion}

Tryptic soy broth is a media that is suitable for the growth of E.coli. The bacterial colonies of E.coli O157:H7 appeared in off white color and rounded in shape in solid media that contains agar in it. Solid media contains agar in it. It provides nourishment to the bacteria

\section{Sorbitol MacConkey Agar}

E.coli forms red colonies. Other gram negative bacterial colonies will not be red rather they will be light pink. E.coli $\mathrm{O} 157: \mathrm{H} 7$ is unable to ferment sorbitol that is present in Sorbitol MacConkey Agar. Lactose is replaced by sorbitol in Sorbitol MacConkey agar. As E.coli O157:H7 cannot ferment sorbitol,so it uses peptone to grow.

\section{Novobiocin}

Novobiocin is an antibiotic that is obtained from the actinomycete Streptomyces niveus. It is also known as albamycin or cathomycin. Novobiocin is an aromatic ether compound. Novobiocin is divided into three parts, a benzoic acid derivative, a coumarin residue and the novobiose sugar. Novobiocin promotes the growth of E.coli O157:H7 and inhibits the growth of other bacteria. Its formula is $\mathrm{C} 31 \mathrm{H} 36 \mathrm{~N} 2 \mathrm{O} 11$ and removal of carbomyl group located on the novobiose sugar results in the inhibitory activity of Novobiocin. It promotes the growth of E.coli $\mathrm{O} 157: \mathrm{H} 7$ and inhibits the growth of other bacteria.

\section{Gram Staining}

In the gram staining,pink color cells were observed, which shows the presence of gram negative bacteria. 


\section{Rearing of Tribolium castaneum:}

The rearing of T.castaneum was done in the laboratory of Lahore College for Women University under appropriate temperature. The glass jars was autoclaved for the rearing of bacteria. In the

Glass jars weighed semolina and $10 \%$ yeast extract was placed as a diet. The temperature required for the growth of T.castaneum is $37.5^{\circ} \mathrm{C}$. A female after mating laid 2-3 eggs per day. These eggs were whitish in color and hatched after 9 days in the semolina and yeast extract. These eggs hatched into slender white larvae tinged with yellow. The larvae passed its 6 instar phases from first instar to second instar in the semolina. After passing 6 instar phases, larvae developed into naked pupa. The pupal period was about 8 days and then it changed into adult. The reared second instar larvae were used for the purpose of bioassay.

\section{Bioassay}

The bioassay method was applied to check the effect of E.coli on Tribolium castaneum by mixing the grown pellet in the diet of T.castaneum. Bioassay was applied in Bioassay glass vials in two groups such as Control group and Experimental group. The Bioassay glass vials were daily observed upto 3 days and 7 days. The rate of mortality in control group and experimental group was approximately $\leq 10 \%$, when observed after 7 days. So E.coli did not show any toxic effect against T.castaneum growth or no morality occurred because of E.coli as shown in table 1 to 8 .

Table 1. Effect of E.coli against larvae of Tribolium castaneum for 3 days at $0.25 \mathrm{~g} / \mathrm{g}$ dose by comparing mortality in Control group and Experimental group

\begin{tabular}{|c|c|c|c|c|c|c|c|c|c|}
\hline \multirow[t]{2}{*}{ Days } & \multicolumn{4}{|c|}{ Control Group } & Dose & \multicolumn{4}{|c|}{ Mortality in Experimental group } \\
\hline & $\mathrm{C} 1$ & $\mathrm{C} 2$ & $\mathrm{C} 3$ & D/A \% Mortality & \multirow{4}{*}{$0.25 \mathrm{~g} / \mathrm{g}$} & R1 & R2 & R3 & D/A \% Mortality \\
\hline 1 & $0 / 10$ & $0 / 10$ & $0 / 10$ & $0 \%$ & & $0 / 10$ & $0 / 10$ & $0 / 10$ & $0 \%$ \\
\hline 2 & $0 / 10$ & $0 / 10$ & $0 / 10$ & $0 \%$ & & $0 / 10$ & $0 / 10$ & $0 / 10$ & $0 \%$ \\
\hline 3 & $1 / 10$ & $0 / 10$ & $0 / 10$ & $3.33 \%$ & & $0 / 10$ & $0 / 10$ & $0 / 10$ & $0 \%$ \\
\hline
\end{tabular}

Table 2. Effect of E.coli against larvae of Tribolium castaneum for 3 days at $0.50 \mathrm{~g} / \mathrm{g}$ dose by comparing the

\begin{tabular}{|c|c|c|c|c|c|c|c|c|c|}
\hline \multirow{2}{*}{ Days } & \multicolumn{4}{|c|}{ Control Group } & \multirow{2}{*}{ Dose } & \multicolumn{4}{|c|}{ Mortality in Experimental group } \\
\hline & $\mathrm{C} 1$ & $\mathrm{C} 2$ & $\mathrm{C} 3$ & D/A \% Mortality & & R1 & R2 & R3 & D/A \% Mortality \\
\hline 1 & $0 / 10$ & $0 / 10$ & $0 / 10$ & $0 \%$ & \multirow{3}{*}{$0.5 \mathrm{~g} / \mathrm{g}$} & $0 / 10$ & $0 / 10$ & $0 / 10$ & $0 \%$ \\
\hline 2 & $0 / 10$ & $0 / 10$ & $0 / 10$ & $0 \%$ & & $0 / 10$ & $0 / 10$ & $0 / 10$ & $0 \%$ \\
\hline 3 & $1 / 10$ & $0 / 10$ & $0 / 10$ & $3.33 \%$ & & $0 / 10$ & $0 / 10$ & $0 / 10$ & $0 \%$ \\
\hline
\end{tabular}

Mortality rate in control and experimental group

Table 3. Effect of E.coli against the larvae of Tribolium castaneum for 3 days at $1.0 \mathrm{~g} / \mathrm{g}$ dose by comparing the Mortality rate in control and experimental group

\begin{tabular}{|c|c|c|c|c|c|c|c|c|c|}
\hline \multirow{2}{*}{ Days } & \multicolumn{4}{|c|}{ Control Group } & \multirow{2}{*}{ Dose } & \multicolumn{4}{|c|}{ Mortality in Experimental group } \\
\cline { 2 - 5 } & $\mathrm{C} 1$ & $\mathrm{C} 2$ & $\mathrm{C} 3$ & D/A \% Mortality & & $\mathrm{R} 1$ & $\mathrm{R} 2$ & $\mathrm{R} 3$ & $\mathrm{D} / \mathrm{A} \%$ Mortality \\
\hline 1 & $0 / 10$ & $0 / 10$ & $0 / 10$ & $0 \%$ & & $0 / 10$ & $0 / 10$ & $0 / 10$ & $0 \%$ \\
\hline 2 & $0 / 10$ & $0 / 10$ & $0 / 10$ & $0 \%$ & \multirow{2}{*}{$1.0 \mathrm{~g} / \mathrm{g}$} & $0 / 10$ & $0 / 10$ & $0 / 10$ & $0 \%$ \\
\hline 3 & $1 / 10$ & $0 / 10$ & $0 / 10$ & $3.33 \%$ & & $0 / 10$ & $0 / 10$ & $0 / 10$ & $0 \%$ \\
\hline
\end{tabular}

Table 4. Effect of E.coli against larvae of Tribolium castaneum for 3 days at $1.50 \mathrm{~g} / \mathrm{g}$ dose by comparing the Mortlity rate in control and experimental group

\begin{tabular}{|c|c|c|c|c|c|c|c|c|c|}
\hline \multirow{2}{*}{ Days } & \multicolumn{4}{|c|}{ Control Group } & \multirow{2}{*}{ Dose } & \multicolumn{4}{|c|}{ Mortality in Experimental group } \\
\hline & $\mathrm{C} 1$ & $\mathrm{C} 2$ & $\mathrm{C} 3$ & D/A \% Mortality & & $\mathrm{R} 1$ & $\mathrm{R} 2$ & R3 & D/A \% Mortality \\
\hline 1 & $0 / 10$ & $0 / 10$ & $0 / 10$ & $0 \%$ & \multirow{3}{*}{$1.5 \mathrm{~g} / \mathrm{g}$} & $0 / 10$ & $0 / 10$ & $0 / 10$ & $0 \%$ \\
\hline 2 & $0 / 10$ & $0 / 10$ & $0 / 10$ & $0 \%$ & & $0 / 10$ & $0 / 10$ & $0 / 10$ & $0 \%$ \\
\hline 3 & $1 / 10$ & $0 / 10$ & $0 / 10$ & $3.33 \%$ & & $0 / 10$ & $0 / 10$ & $0 / 10$ & $0 \%$ \\
\hline
\end{tabular}


Table 5. Effect of E.coli against larvae of Tribolium castaneum for 7 days at $0.25 \mathrm{~g} / \mathrm{g}$ dose, by comparing the Mortality rate in control and experimental group

\begin{tabular}{|c|c|c|c|c|c|c|c|c|c|}
\hline \multirow{2}{*}{ Days } & \multicolumn{4}{|c|}{ Control Group } & \multirow{2}{*}{ Dose } & \multicolumn{4}{|c|}{ Mortality in Experimental group } \\
\hline & $\mathrm{C} 1$ & $\mathrm{C} 2$ & $\mathrm{C} 3$ & D/A \% Mortality & & $\mathrm{R} 1$ & $\mathrm{R} 2$ & R3 & D/A \% Mortality \\
\hline 1 & $0 / 10$ & $0 / 10$ & $0 / 10$ & $0 \%$ & \multirow{7}{*}{$0.25 \mathrm{~g} / \mathrm{g}$} & $0 / 10$ & $0 / 10$ & $0 / 10$ & $0 \%$ \\
\hline 2 & $0 / 10$ & $0 / 10$ & $0 / 10$ & $0 \%$ & & $0 / 10$ & $0 / 10$ & $0 / 10$ & $0 \%$ \\
\hline 3 & $1 / 10$ & $0 / 10$ & $0 / 10$ & $3.33 \%$ & & $0 / 10$ & $0 / 10$ & $0 / 10$ & $0 \%$ \\
\hline 4 & $1 / 10$ & $0 / 10$ & $0 / 10$ & $3.33 \%$ & & $0 / 10$ & $1 / 10$ & $0 / 10$ & $3.33 \%$ \\
\hline 5 & $1 / 10$ & $1 / 10$ & $1 / 10$ & $10 \%$ & & $0 / 10$ & $1 / 10$ & $1 / 10$ & $6.66 \%$ \\
\hline 6 & $1 / 10$ & $1 / 10$ & $1 / 10$ & $10 \%$ & & $1 / 10$ & $1 / 10$ & $1 / 10$ & $10 \%$ \\
\hline 7 & $1 / 10$ & $1 / 10$ & $1 / 10$ & $10 \%$ & & $1 / 10$ & $1 / 10$ & $1 / 10$ & $10 \%$ \\
\hline
\end{tabular}

Table 6. Effect of E.coli against larvae of Tribolium castaneum for 7 days at $0.50 \mathrm{~g} / \mathrm{g}$ dose, by comparing

\begin{tabular}{|c|c|c|c|c|c|c|c|c|c|}
\hline \multirow{2}{*}{ Days } & \multicolumn{4}{|c|}{ Control Group } & \multirow{2}{*}{ Dose } & \multicolumn{4}{|c|}{ Mortality in Experimental group } \\
\hline & $\mathrm{C} 1$ & $\mathrm{C} 2$ & $\mathrm{C} 3$ & D/A \% Mortality & & $\mathrm{R} 1$ & $\mathrm{R} 2$ & R3 & D/A \% Mortality \\
\hline 1 & $0 / 10$ & $0 / 10$ & $0 / 10$ & $0 \%$ & \multirow{7}{*}{$0.5 \mathrm{~g} / \mathrm{g}$} & $0 / 10$ & $0 / 10$ & $0 / 10$ & $0 \%$ \\
\hline 2 & $0 / 10$ & $0 / 10$ & $0 / 10$ & $0 \%$ & & $0 / 10$ & $0 / 10$ & $0 / 10$ & $0 \%$ \\
\hline 3 & $1 / 10$ & $0 / 10$ & $0 / 10$ & $3.33 \%$ & & $0 / 10$ & $0 / 10$ & $0 / 10$ & $0 \%$ \\
\hline 4 & $1 / 10$ & $0 / 10$ & $0 / 10$ & $3.33 \%$ & & $0 / 10$ & $1 / 10$ & $0 / 10$ & $3.33 \%$ \\
\hline 5 & $1 / 10$ & $1 / 10$ & $0 / 10$ & $6.66 \%$ & & $0 / 10$ & $1 / 10$ & $1 / 10$ & $6.66 \%$ \\
\hline 6 & $1 / 10$ & $1 / 10$ & $1 / 10$ & $10 \%$ & & $1 / 10$ & $1 / 10$ & $1 / 10$ & $10 \%$ \\
\hline 7 & $1 / 10$ & $1 / 10$ & $1 / 10$ & $10 \%$ & & $1 / 10$ & $1 / 10$ & $1 / 10$ & $10 \%$ \\
\hline
\end{tabular}

the Mortality rate in control and experimental group

Table 7.Effect of E.coli against larvae of Tribolium castaneum for 7 days at $1.0 \mathrm{~g} / \mathrm{g}$ dose, by comparing the Mortality rate in control and experimental group

\begin{tabular}{|c|c|c|c|c|c|c|c|c|c|}
\hline \multirow{2}{*}{ Days } & \multicolumn{4}{|c|}{ Control Group } & \multirow{2}{*}{ Dose } & \multicolumn{4}{|c|}{ Mortality in Experimental group } \\
\hline & $\mathrm{C} 1$ & $\mathrm{C} 2$ & C3 & D/A \% Mortality & & $\mathrm{R} 1$ & $\mathrm{R} 2$ & R3 & D/A \% Mortality \\
\hline 1 & $0 / 10$ & $0 / 10$ & $0 / 10$ & $0 \%$ & \multirow{7}{*}{$1.0 \mathrm{~g} / \mathrm{g}$} & $0 / 10$ & $0 / 10$ & $0 / 10$ & $0 \%$ \\
\hline 2 & $0 / 10$ & $0 / 10$ & $0 / 10$ & $0 \%$ & & $0 / 10$ & $0 / 10$ & $0 / 10$ & $0 \%$ \\
\hline 3 & $0 / 10$ & $0 / 10$ & $0 / 10$ & $0 \%$ & & $0 / 10$ & $0 / 10$ & $0 / 10$ & $0 \%$ \\
\hline 4 & $1 / 10$ & $0 / 10$ & $0 / 10$ & $3.33 \%$ & & $0 / 10$ & $1 / 10$ & $0 / 10$ & $3.33 \%$ \\
\hline 5 & $1 / 10$ & $1 / 10$ & $0 / 10$ & $6.66 \%$ & & $0 / 10$ & $1 / 10$ & $1 / 10$ & $6.66 \%$ \\
\hline 6 & $1 / 10$ & $1 / 10$ & $1 / 10$ & $10 \%$ & & $1 / 10$ & $1 / 10$ & $1 / 10$ & $10 \%$ \\
\hline 7 & $1 / 10$ & $1 / 10$ & $1 / 10$ & $10 \%$ & & $1 / 10$ & $1 / 10$ & $1 / 10$ & $10 \%$ \\
\hline
\end{tabular}

Table 8.Effect of E.coli against larvae of Tribolium castaneum for 7 days at $1.50 \mathrm{~g} / \mathrm{g}$ dose, by comparing the Mortality rate in control and experimental group

\begin{tabular}{|c|c|c|c|c|c|c|c|c|c|}
\hline \multirow{2}{*}{ Days } & \multicolumn{4}{|c|}{ Control Group } & \multirow{2}{*}{ Dose } & \multicolumn{4}{|c|}{ Mortality in Experimental group } \\
\hline & $\mathrm{C} 1$ & $\mathrm{C} 2$ & C3 & D/A \% Mortality & & $\mathrm{R} 1$ & $\mathrm{R} 2$ & R3 & D/A \% Mortality \\
\hline 1 & $0 / 10$ & $0 / 10$ & $0 / 10$ & $0 \%$ & \multirow{7}{*}{$1.5 \mathrm{~g} / \mathrm{g}$} & $0 / 10$ & $0 / 10$ & $0 / 10$ & $0 \%$ \\
\hline 2 & $0 / 10$ & $0 / 10$ & $0 / 10$ & $0 \%$ & & $0 / 10$ & $0 / 10$ & $0 / 10$ & $0 \%$ \\
\hline 3 & $1 / 10$ & $0 / 10$ & $0 / 10$ & $3.33 \%$ & & $0 / 10$ & $0 / 10$ & $0 / 10$ & $0 \%$ \\
\hline 4 & $1 / 10$ & $0 / 10$ & $0 / 10$ & $3.33 \%$ & & $0 / 10$ & $1 / 10$ & $0 / 10$ & $3.33 \%$ \\
\hline 5 & $1 / 10$ & $1 / 10$ & $0 / 10$ & $6.66 \%$ & & $0 / 10$ & $1 / 10$ & $1 / 10$ & $6.66 \%$ \\
\hline 6 & $1 / 10$ & $1 / 10$ & $1 / 10$ & $10 \%$ & & $1 / 10$ & $1 / 10$ & $1 / 10$ & $10 \%$ \\
\hline 7 & $1 / 10$ & $1 / 10$ & $1 / 10$ & $10 \%$ & & $1 / 10$ & $1 / 10$ & $1 / 10$ & $10 \%$ \\
\hline
\end{tabular}

The present study was done to examine the entomopathogenic effect of Escherichia coli against the Tribolium castaneum so that it can be used as a biopesticide. It was found through the literature review that no work has been done for finding the toxic effects of Ecoli on T.castaneum. The main objective of this study was based on the ability of the pathogenic E.coli to cause severe illness in human beings and to check the same 
effect on the stored grain pest such as T.castaneum as well. Another aspect of this study was to get experience in Microbial techniques, Entomological techniques like insect rearing technique and Biotoxicity assay technique. The present study is based on the basic mechanism of pathogenecity of E.coli in human beings. Enterohemorrhagic E.coli $\mathrm{O} 157: \mathrm{H} 7$ has a ability to produce potent cytotoxins but besides these toxins, it has the ability to produce a protein called Intimin that is probably responsible for the intimate attachment of STEC to the intestinal epithelial cells leading to the damage of the epithelial and produces lesions. The gene that encodes this protein is eaeA. Enterohemorrhagic E.coli O157:H7 form characterics lesions called attaching and effacing lesions (AE) on the infected mammalian intestinal cells. The AE lesions are characterized by the loss of microvilli,intimate adherence of bacteria adjacent to the host cell memberane and organized cytoskeletal structures are generated containing filamentous actin beneath bacterial sites attachment called actin pedestals. When the Bioassay was applied, there was no mortality shown which indicates that E.coli O157:H7 does not effect the growth of T.castaneum and also does not produce any disease in T,castaneum. The aim of this study was based on the comparison with the mechanism of pathogenecity of E.coli O157:H7 in human beings. The basic idea was to find the same mechanism of pathogenecity in T.castaneum. This pathogen injects its own translocated intimin(Tir) receptor molecule into the plasma memberane of host cells. Interaction of translocated Tir with the bacterial outer membrane accur. Protein intimin is required to trigger the assembly of actin into focused pedestals beneath bound bacteria. This causes lesions in human beings and causes pathogenecity. But in case of Tribolium castaneum, no pathogenecity results by the effect of E.coli O157:H7. This shows that the pathogen may not inject its own translocated Tir receptor molecule into the plasma memberane of Tribolium castaneum, which is important for the pathogenecity. Finally in the present research, it was found that E.coli O157:H7 did not effect the growth of Tribolium castaneum and no mortality results. So it could not be used as a Biopesticide.

\section{Conclusion}

In the present study, human pathogenic bacteria E.coli were mixed in the diet of T.castaneum to analyse its pathogenic effect on the stored grain pest. Samples of E.coli from raw meat samples were cultured on different media such as TSB, MacConkey and Novobiocin media and then this bacteria was mixed with the diet of T.castaneum. From the results, it was observed that E.coli does not have any effect on the T.castaneum growth. E.coli is pathogenic to human beings. The adherence of E.coli to the human intestinal wall is necessary for the pathogenecity of E.coli. A specific protein intimin is present at the cell wall of the E.coli. Intimin attached to the Translocated intimin (Tir) receptor. This pathogen injects its own translocated intimin (Tir) receptor molecule into the plasma memberane of host cells and leading to the damage of the epithelial of intestinal wall and attaching and effacing (A/E) lesions are produced. So Translocated intimin (Tir) receptor is required for the proper attachment and for initiating the pathogenesis. From the results, it was observed that E.coli does not have any effect on the T.castaneum growth. So it was concluded that E.coli O157:H7 may not inject its own Translocated intimin (Tir) receptor into the intestinal cells of Tribolium castaneum and no pathogenic effect is shown in T.casataneum.

\section{References}

[1] O., Clermont, S. Bonacorsi and E. Bingen, Rapid and simple determination of the Escherichia coli Phylogenetic group. Appl. Environ. Mirobiol. 66(10), 2000, 4555-4558.

[2] B. S. Drasar, and P. A. Barrow, Intestinal Microbiology. In: Amer.Soc. Microbiol. Press, Washington, D C. 1985, 19-40.

[3] M. T. Medigan, and J. M. Martinko, Brock Biology of microorganisms. $11^{\text {th }}$ ed. Pearson Prentice Hall, USA. 2006, 234-456.

[4] Hatch and M. Duane, Biotinylated Bi- and Tetra-antennary Glycoconjugates for Escherichia coli Detection. Chem Bio Chem. 9, 2008, 2433-2442.

[5] A. C. Sonnenwirth, Davis, Harper, Row and M.D. Hagerstown, The Enteric Bacilli and Similar Gram- Negative Bacteria. In: Microbiology. $2^{\text {nd }}$ ed. 1973, 788-789.

[6] O. Roth and J. Kurtz, The stimulation of immune defence accelerates development in the red flour beetle (Tribolium castaneum). J. Evol. Biol. 21(6), 2008, 1703-1710.

[7] Y. Park, A. Aikins, J. L. Wang, W.R. Beeman, B. Oppert, C. J. Lord, J. S. Brown, D. M. Lorenzen, S. Richards, M. J. Weinstock, and A. G. Gibbs, Analysis of transcriptome data in the red flour beetle, Tribolium castaneum. Insect. Biochem. Mol. Biol. 38(4), 2008, 380-386.

[8] M. S. Donnenberg, A. Donohue-Rolfe, and G.T. Keusch, Epithelial cell invasion: an overlooked property of enteropathogenic Escherichia coli (EPEC) associated with the EPEC adherence factor. J. Infect. Dis. 160 (3), 1989, 452-459.

[9] M. D. Milidis, H. J. Koomhof, and J. L. Philips. Invasive potential non cytotoxic enteropathogenic E. coli in an in-vitro Henle 407 cell model. Infect. Immun.57, 1989, 1928-1935.

[10] T. G. Cleary, Cytotoxin-producing Escherichia coli and the hemolytic uremic syndrome. Pediatr. Clin. North. 35, 1988, 485-501.

[11] A. D. O'Brien, and G. D. Leveck, Purification and characterization of Shigella dysenteria 1-like toxin produced by E. coli. Infect. Immun. 40, 1983, 675-683.

[12] K. Todar, "Pathogenic E. coli". Online Textbook of Bacteriology. University of Wisconsin-Madison. Department of Bacteriology. 2007, 34-67.

[13] M. A. Islam, A. S. Mondol, E. Boer, R. R. Beumer, M. H. Zwietering, K. A. Talukder, and A. E. Heuvelink. Prevalence and genetic characterization of shiga toxin-producing Escherichia coli isolates from slaughtered animals in Bangladesh. Appl. Environ. Microbiol. 74(17), 2008, 5414-5421. 
[14] T. R. Callaway, R. O. Elder, J. E. Keen, R. C. Anderson, D. J. Nisbet. Forage feeding to reduce preharvest Escherichia coli populations in cattle, a review. J. Dairy. Sci. 86, 2003, 852-860.

[15] W. E. Burkholder, and D. L. Faustini, Biological methods of survey and control. In: Gorham JR, editor. Ecology and Management of Food Industry Pests. 1991, 361-372.

[16] M. A. Saleem, and A. R. Shakoori, The toxicity of eight insecticides to sixth instar larvae and adult beetles of T.castaneum(Herbst.).Pak. J. Zool. 22, 1990, 207-216.

[17] D. J. B. Dalzell, S. Alte, E. Aspichueta, A. Sota, J. Etxebarria, M. Gutierrez, C. C. Hoffmann, D. Sales, U. Obst, and N. Christofi, A comparison of five rapid direct toxicity assessment methods to determine toxicity of pollutants to activated sludge. Chemosphere. 47(5), 2002, 535-545.

[18] G. K. Campelone, and M. J. Leong, Tails of two Tirs:actin pedestal formation by enteropathogenic E.coli and Enterohemorrhagic E.coli O157:H7. Curr. Opin. Microbiol. 6, 2003, 82-89. 